\title{
Factors affecting the adoption and use of urban air mobility
}

\author{
Christelle Al Haddad ${ }^{\mathrm{a}, *}$, Emmanouil Chaniotakis ${ }^{\mathrm{b}}$, Anna Straubinger ${ }^{\mathrm{c}}$, Kay Plötner ${ }^{\mathrm{c}}$, Constantinos \\ Antoniou $^{\mathrm{a}}$ \\ ${ }^{a}$ Chair of Transportation Systems Engineering, Technical University of Munich, Arcisstrasse 21, 80333 Munich, Germany \\ ${ }^{b}$ MaaSLab, Energy Institute, University College London, 14 Upper Woburn Place, WC1HONN London, UK \\ ${ }^{c}$ Bauhaus Luftfahrt e.V., Willy-Messerschmitt-Strasse 1, 82024 Taufkirchen, Germany
}

\begin{abstract}
Technological advances have recently led to the development of urban air mobility (UAM), an alternative transportation mode with several concepts including vehicles operated by on-demand fully-automated vertical take-off and landing aircraft (VTOL) for intra-city passenger transportation. However, despite a growing interest in UAM, understanding users' perceptions to it remains limited. This research aims to identify and quantify the factors affecting the adoption and use of UAM, based on relevant tools from the literature, such as recurring factors in studies on aerial vehicle concepts, ground autonomous vehicles, but also acceptance models, such as the Technology Acceptance Model by Davis et al. (1989). A stated-preference survey was developed to assess the perception of users in terms of adoption time horizon, including options such as the first six years of the service's implementation, "unsure", and "never". The obtained results were evaluated using exploratory factor analyses, and the specification and estimation of suitable discrete choice models, multinomial logit models (MNLs) and ordered logit models (OLMs), with adoption time horizon as dependent variable. Findings revealed the importance of safety and trust, affinity to automation, data concerns, social attitude, and socio-demographics for adoption. Factors, such as the value of time savings, the perception of automation costs, and service reliability, were also found to be highly influential. There was also an indication that skeptical respondents, i.e. answering "unsure", had a behavior similar to late and non-adopters, i.e. adoption time horizon higher than six years or answering "never". The summarized results were represented in an extended Technology Acceptance Model for urban air mobility, and provided insights for policymakers and industrial stakeholders.
\end{abstract}

Keywords: urban air mobility, adoption, acceptance, technology acceptance model, perception, stated preference, exploratory factor analysis, discrete choice modeling

\section{Introduction}

Shared mobility services are providing users with more efficient travel options, characterized by lower demand for parking spaces, lower vehicle ownership, but also reduced environmental impacts resulting from lower emissions (Baptista et al., 2014). At the same time, autonomous vehicles promise safe and comfortable 5 transportation, and most automobile manufacturers are likely to launch fully autonomous vehicles in the coming decade (Bimbraw, 2015). This trend has led to a research interest in ground shared autonomous mobility (Fagnant \& Kockelman, 2014), and possibly to the exploration of the third dimension: the skyscape. This has been reflected in aerial vehicle concepts for passenger transportation, also called as "urban air mobility" (UAM). The concepts for short-haul passenger air trips are facilitated by technological advances

\footnotetext{
* Corresponding author

Email addresses: christelle.haddad@tum.de (Christelle Al Haddad), m.chaniotakis@ucl.ac.uk (Emmanouil Chaniotakis), Anna.Straubinger@bauhaus-luftfahrt.net (Anna Straubinger), Kay.Ploetner@bauhaus-luftfahrt.net (Kay Plötner), c.antoniou@tum.de (Constantinos Antoniou)
} 
in terms of battery storage, electrical power transmission and distributed propulsion systems (Shamiyeh et al., 2017). The US National Aeronautics and Space Administration (NASA) is developing a framework for the integration of urban air mobility airspace research with the efforts of different partners and stakeholders (Thipphavong et al., 2018). For instance, Airbus (2018) introduces urban air mobility as the integration of the third dimension to urban transport networks, including the on-demand sharing mobility operated by 15 vertical take-off and landing aircraft (VTOL) for intra-city passenger trips, with a long-term vision entailing electrical self-piloted VTOLs, such as Vahana and CityAirbus demonstrators, for one or more passengers respectively. The introduction of urban air mobility, according to Airbus (2017), promises to offer a safer, more reliable, and more environmental alternative to alleviate congestion on transport networks. Currently, Voom (an Airbus company) is providing on-demand helicopter bookings in megacities like Mexico City and São Paulo, laying the ground for further developments in urban air mobility (Airbus, 2018). Uber has also introduced air taxi models in their business plans, such as the economic model assuming a four-seat capacity (including the pilot if the vehicle is not self-piloted), for which passengers have the possibility to share the flight and thereby save on the ride cost (Uber Elevate, 2016). Porsche Consulting (2018) defines the process of this service as follows: starting from the first mile (access to the vertiport), followed by the boarding 25 on the vehicle, the flight time (including take-off and landing), the de-boarding, and finally the last mile transfer; the service can be booked online and the assumed boarding and de-boarding times are around three minutes each. In this study, Porsche Consulting (2018) presents three e-VTOL concepts with different certification times, travel speeds (from 70 to $300 \mathrm{~km} / \mathrm{h}$ ), routes, and purposes (intra- and/or intercity trips), projecting for 2035 a passenger market of around 23000 aircraft and worth $\$ 32$ Billion.

Despite different model definitions, urban air mobility is constrained by many aspects related to regulations, infrastructure availability, air traffic control, environmental impacts, but also community acceptance (Vascik, 2017). In terms of infrastructure challenges, Cohen (1996) studied vertiport prototypes to optimize land use, site selection, and community acceptance and more recently Fadhil (2018) focused on a GIS-based analysis for ground infrastructure selection for urban air mobility. In modeling UAM impacts, the service 35 implications on the inhabitants and the changes on the city were evaluated (Straubinger \& Verhoef, 2018), but also an agent-based simulation and an initial analysis of the service's performance were conducted (Rothfeld et al., 2018).

To better understand the service demand and to be able to predict it, understanding consumer adoption is crucial; in other words, if and when users are going to use urban air mobility. For instance, a study from 40 the Georgia Institute of Technology designed a survey to collect responses from 2,500 high-income workers in different areas of the US to predict their demand for eVTOL in urban areas, with flights ranging up to $90 \mathrm{~km}$ (Garrow et al., 2018). Passenger adoption in a UAM environment was also explored using choice modeling in a case study based in Munich (Fu et al., 2019). Setting the context for the characteristics that imply the use of VTOL, Antcliff et al. (2016) proposes Silicon Valley as an ideal region for early introduction

45 of on-demand civil VTOL operations, mostly due to good weather, high housing prices, high incomes, but also number of hyper commuters (those who commute two or more hours per day) who would greatly reduce their time in congestion (Antcliff et al., 2016). In Germany, research on UAM has targeted the city of Ingolstadt as part of the "Urban Air Mobility Initiative", supported by the European Commission.

Vascik \& Hansman (2018) emphasized the significance of noise and altitude levels as areas of concerns 50 for community acceptance of urban air mobility systems. To the best of the authors' knowledge, however, the acceptance of urban air mobility has not yet been investigated in terms of users' profiles (not related to the service characteristics) outside of a mode choice context, and in relation to adoption time horizon. This paper helps to fill this gap by developing a framework for UAM adoption and use, assuming an ondemand intra-city passenger transportation, operated by fully-automated electric VTOL, integrated with 55 public transportation systems, with the possibility to ride-pool (share the ride with other passengers to save money). This is based on the development of a novel stated preference survey design with adoption time horizon as a dependent variable, aiming to reveal factors affecting adoption of this service. Futuristic scenarios were introduced to evaluate a hypothetical system starting in 2030, aiming to better understand if and when users would adopt them, but also the barriers and opportunities from a behavioral perspective. 60 Accordingly, factors were identified by exploring those found to be significant in the perception of aerial vehicle concepts, in technology and automation acceptance models, and affecting automation acceptance in 
transport. This research contributes to the existing body of literature on the acceptance and adoption of new forms of mobility by presenting a novel methodological approach using a non-conventional dependent variable for ordered logit models: time variable in a scale including a non-ordinal parameter, such as

65 "unsure", as to the best of the authors' knowledge these models are mostly used with ordinal scales, such as Likert scales, for attitudes and satisfaction. The obtained results are represented in a Technology Acceptance Model for urban air mobility that could be generalized for disruptive transport technologies. The significantly identified factors offer a good basis for the investigation of more realistic scenarios in a nearer future, as they show an aptitude of users towards them.

The remainder of this paper is structured as follows. A literature review is first presented, followed by the methods used including the survey design, descriptive analysis and model development, and study limitations. The data collected and main statistical results are then derived. After that, the developed and estimated models are shown, namely the exploratory factor analyses and discrete choice models. Then, a discussion of the main survey findings is presented along with the proposed Technology Acceptance Model 75 for Disruptive Transport Technologies, and the policy level insights and recommendations. Industrial stakeholders could thereby appropriately care for the needs of different classes of users, while policymakers could benefit from these factors by setting guidelines or more stringent regulations if required. Finally, a conclusion is drawn with some recommendations on future relevant work.

\section{Literature review}

To examine the adoption of a new service, pertinent literature suggests that it is necessary to understand the conditions for trusting this service and accepting its operational characteristics. In the case of UAM, this inevitably passes through the investigation of technology and automation acceptance models, and of factors commonly affecting the acceptance of automation in transport. As only a few studies have explicitly focused on consumer adoption of urban air mobility, examining studies on community acceptance of other aerial vehicles or services might be useful despite its limitations.

\subsection{Factors affecting aerial vehicles perception}

Recent studies commissioned by NASA investigated market potentials for urban air mobility, focusing on the different barriers to its implementation, including community acceptance and key factors for its users and non-users' adoption. The study commissioned to Crown Consulting studied the viability of three

90 UAM use cases in 15 US cities (NASA, 2019): last mile delivery (for packages), air metro (an autonomous public transit style commuter system) and air taxi (an autonomous on-demand ridesharing system). This study revealed that nearly half of all surveyed consumers were potentially comfortable with delivery and UAM use cases. Major concerns presented were safety, privacy, job security, environmental threats and noise and visual pollution. Moreover, cybersecurity, affordability and willingness to pay were perceived as 95 barriers to the UAM viability. The study commissioned to Booz Allen Hamilton (NASA, 2018) looked at three potential UAM markets (airport shuttle, air taxi and air ambulance) in ten target urban areas, to explore market size and barriers, understand the potential viability of the use cases, but also the societal and environmental impacts of UAM; this study included a survey, focus groups, and stakeholder interviews. Societal barriers were analyzed by looking at both user and non-user perspectives. Key factors were safety

100 (including passengers' need for security screening), privacy and noise, preference for piloted aircraft, impact of having a flight attendant, cybersecurity, cost and convenience, but also socio-demographics; men (along with millennials and younger respondents) were found to be more comfortable and willing to use UAM.

In a stated preference survey based in Munich, Fu et al. (2019) explored transportation mode preferences in an Urban Air Mobility environment including four alternatives: private car, public transportation, au-

105 tonomous taxi, and autonomous flying taxi (or UAM). The study results indicated that travel time, travel cost, and safety might be critical for determining UAM adoption. Socio-demographics were also found as highly influential in UAM use, as market segments showed that younger individuals as well as older ones with higher household income are more likely to adopt UAM. Also, trip purpose proved to be significant, with non-commuting being the respondents' most preferred option. 
Research on consumer acceptance of unmanned civilian drones identified common concerns among people, such as privacy (Wang et al., 2016; Clothier et al., 2015), risks associated with accidents, and security regarding the recognition of drones used for emergency (Lidynia et al., 2017). Additionally, Chamata (2017) identified social and economic concerns as factors delaying the adoption of civilian drones. According to the trip purpose, the community acceptance of drones might differ (Boucher, 2016). For unmanned aerial vehicles (UAV), MacSween (2003) found that emotional and safety data increased users' persuasions of UAV applications, including commercial, cargo, and passenger transportation. Whereas the above concerns apply to community acceptance of drones, they could be very relevant to consumer adoption of UAM, as they all discuss users' perceptions of unmanned aviation.

A stated preference study by Peeta et al. (2008) investigating the travel propensity towards air taxi service, defined as very light jet-based on-demand air service (ODAS), predicted the probability of individuals of switching from their usual mode of intercity transportation to an on-demand air service (ODAS) given a set of scenarios of travel distance and cost. The adoption of ODAS was found to be highly dependent on travel distance, service fare, and level of accessibility. Kreimeier \& Stumpf (2017) found cost to be crucial in determining consumer adoption in Germany. The market share for thin-haul on-demand air mobility services has been estimated as $19 \%$ or 235 million trips per year, based on a choice model assuming 0.1 $€ / \mathrm{km}$ costs gap between UAM services and cars; a sensitivity analysis showed that this volume would drop to 24 million for a gap of $0.2 € / \mathrm{km}$. This market would be potentially viable for distances above $100 \mathrm{~km}$, with $60 \%$ of the market expected for distances between 200 and $400 \mathrm{~km}$ (inter-city). Both studies by Peeta et al. (2008) and Kreimeier \& Stumpf (2017) presented inter-city applications or thin-haul flights, which are arguably different than intra-city application of UAM; however, they still highlighted cost and time as significant factors for consumer adoption of on-demand aerial mobility.

\subsection{Technology and automation acceptance models}

Technology acceptance has long been an area of interest in research with the main purpose of modeling how people accept and use a technology. Perhaps the most renown technology acceptance model is the Technology Acceptance Model (TAM) by Davis et al. (1989), developed to investigate technology use of information systems, particularly computer technology, in which the correlation between the intention to use and actual usage is measured. The main aim of the model is to present a framework for modeling the user acceptance in terms of factors that influence his or her decision in using the technology. This model is based on two main constructs: the perceived usefulness (PU) and the perceived ease of use (PEU), where PEU reinforces PU. The former is the extent to which the user believes the technology use would enhance his or her job performance, whereas the latter is the degree to which using the technology requires effort. Both factors determine the user attitude towards using the system, which in turn determine the behavioral intention (BI) to use the system, and then the actual system use. This model also includes external variables, which affect the defined constructs. Based on this model, the Technology Acceptance Model 2 (TAM2) was extended by (Venkatesh \& Davis, 2000), impacting the perceived usefulness of the technology. Social influence includes subjective norms, voluntariness, image; cognitive processes included job relevance, output quality, and result demonstrability. In TAM2, these main factors directly influence user perception (PU and PEU). A further revision extended TAM into the Unified Theory of Acceptance and Use of Technology (UTAUT), (Venkatesh et al., 2003), and a later revision into 3enkatesh \& Bala, 2008). According to Ghazizadeh et al. (2012), the UTAUT offers a more complete account of acceptance in comparison with TAM2. In UTAUT, three constructs directly determine BI: performance expectancy, effort expectancy, and social influence (as defined in TAM2); facilitating conditions is a fourth construct that directly determines the use behavior. Gender, age, experience, and voluntariness moderate the impact of the four constructs. The role of moderating factors (factors impacting adoption and reducing the limitations of the models' explanatory power) has been found crucial (Sun \& Zhang, 2006) in technology acceptance models; for instance, the moderating effects of gender and self-efficacy in the context of mobile payment adoption (Riad et al., 2014).

To combine constructs from TAM models with those from the Cognitive Engineering literature, Ghazizadeh et al. (2012) proposed a framework for automation acceptance model (AAM), by adding two main 
experience with automation, existing work practices, work style, and values; the latter (trust) influences BI directly and indirectly through PU and PEU. The model is also reinforced by the feedback mechanisms of the different constructs. Zhang et al. (2019) used structural equation modeling to test hypotheses on their proposed autonomous vehicles acceptance model, in which initial trust is the most critical factor in promoting a positive attitude towards using autonomous vehicles, which along with perceived usefulness determine the behavioral intention (to use autonomous vehicles). In this model, initial trust is affected by perceived usefulness, perceived ease of use, but also two types of risk: the perceived safety risk and the perceived privacy risk; initial trust can be improved by enhancing perceived usefulness or by reducing perceived safety risk. More recently, a study at the University of St.Gallen in Switzerland developed an adapted TAM for personal autonomous mobility, focusing on ground autonomous vehicles (Jenkins et al., 2018). The main additions in automation-related models could serve as a motivation for the extension or application of an urban air mobility acceptance model.

\subsection{Factors affecting automation acceptance in transport}

Social acceptance is a widely researched area in the field of automation, particularly for ground autonomous vehicles ${ }^{1}$. In a study on the trust and acceptance of shared autonomous vehicles $\left(\mathrm{SAE}^{2}\right.$ level 4$)$, Merat et al. (2016) summarized the factors influencing the use of conventional ride-sharing vehicles, but also those affecting the acceptance and trust of robotic systems, where trust includes reliability and safety. Choi \& Ji (2015) also noted the importance of trust in adopting autonomous vehicles; by conducting a survey of 552 drivers and analyzing the data using partial least squares, they noted the importance of perceived locus of control or situation management for gaining trust. Nees (2016) found that realistic expectations, and thereby perceived reliability, are influential in user acceptance of autonomous vehicles. In urban areas in particular, passenger security as part of perceived safety has been noted as crucial for gaining trust (and thereby the implementation and adoption of AVs); especially during the night (Piao et al., 2016). The user's feeling of safety could depend on the vehicle's interior (Merat et al., 2016), but might also be hindered 185 by cyber-security concerns (Kyriakidis et al., 2015). In Germany, 90\% of the respondents of a study on autonomous driving stated that they would feel safer, if they were able to intervene or control the vehicle at any time, or at least in case of emergency (Deloitte Analytics Institute, 2017). Control has also been associated with feeling more independent (Gaggi, 2017) and proved to positively impact the user's perceived ease of use (Rödel et al., 2014). Overall, users have to be aware and convinced of the benefits of the new 190 technology in order to be able to trust it and therefore use it. Manufacturers' reputation could be a positive factor in gaining this trust (Deloitte Analytics Institute, 2017). Real-life tests for autonomous vehicles and a higher transparency in demonstrating the new modes could also lead to a higher trust through an increased user awareness (Bjørner, 2015; Choi \& Ji, 2015).

A higher perception of the benefits of automation could help users gain trust to use the technology, which is reflected in a higher perceived usefulness. A decrease in congestion and improvement of road safety are associated with social benefits (Kaan, 2017) resulting from the reduced number of road crashes. Improved mobility for mobility-impaired users (Clements \& Kockelman, 2017) can be seen as another social benefit. Moreover, the trip purpose could play a role in behavioral intention. Users might be more interested in using autonomous vehicles for leisure trips, after alcohol consumption (Connected Automated Driving EU, 2017), or if the intended trip is unpleasant (Deloitte Analytics Institute, 2017). The perceived advantages of automation may lead to a higher perceived usefulness, resulting in a higher user acceptance. Ease of use in terms of effort expectancy in the case of autonomous vehicles, or ease of access for dependents or mobility-impaired users (Merat et al., 2016) might influence the intention to use autonomous vehicles. For UAM, however, the perceived ease of use (PEU) is not related to effort expectancy or driver intervention, like in the case of ground AVs, as users are not expected at any time to take control of the air vehicle; instead PEU could be translated to simply the booking and boarding processes, since these are the only tasks expected from the users.

\footnotetext{
${ }^{1}$ For practical reasons, the term "autonomous vehicles" will be used to refer to autonomous ground vehicles, and abbreviated with AV. Otherwise, the term urban air mobility or on-demand air mobility will be used to refer to autonomous air vehicles.

${ }^{2}$ Society of Automotive Engineers
} 
Attributes, such as time (Krueger et al., 2016) and costs (Merat et al., 2016), were found to be highly influential in the acceptance of autonomous vehicles. Comfort (Rychel, 2016), vehicle cleanliness (Merat et al., 2016), and availability in different weather conditions (Merat et al., 2016) proved to impact the intention to use; the latter may also be influenced by social behavior, including the willingness to share the ride with strangers (Merat et al., 2016) and the perceived fun of driving or driving enjoyment (Bjørner, 2015). Social attitudes can also include concerns from the loss of jobs induced by automation (Deloitte Analytics Institute, 2017), concerns regarding terrorism, crime, or cyber-security in general, data concerns, such as data protection, data use, or privacy in broader terms (Kyriakidis et al., 2015), but also cultural values since acceptance and adoption vary globally. In industrialized countries, for example, automated vehicles might face higher skepticism compared to emerging countries like India or China (Rychel, 2016). As in the former accident rates are lower, due to higher measures of safety, people might be more reluctant towards automation, as they are not necessarily convinced of its benefits. Also, in more developed countries, users are less likely to be comfortable with their data being shared or used (Kyriakidis et al., 2015).

Socio-demographic factors were mentioned in several studies focusing on automation perception (Rödel et al., 2014; Kyriakidis et al., 2015; Payre et al., 2014). Women were often found to have a lower intention to use autonomous vehicles, compared to their male counterparts (Hohenberger et al., 2016); in contrast, young individuals (Deloitte Analytics Institute, 2017) and individuals with multimodal travel patterns (Krueger et al., 2016) were found to be more likely to adopt shared autonomous vehicles. Similarly, technology awareness was a positive impact on autonomous vehicles acceptance; this includes, for instance, having heard of Google cars (Bansal et al., 2016), autonomous vehicles (Schoettle \& Sivak, 2014), and/or previous experience with advanced driver-assistance systems (ADAS).

\section{Methods} German (DE).

The first and last parts of the survey targeted respondents' travel behavior and socio-demographics, respectively. In the first part, respondents were asked about their commute behavior, their satisfaction with the public transportation system of their region, and their attitudes towards automated systems (enjoyment, trust, perceived usefulness, and previous experience with automation). As these attitudes are commonly

240 found in technology acceptance and use, but are rather difficult to measure directly, they were assessed through (five-point) Likert scale agreement statements (Likert, 1932), with options ranging from "strongly disagree" to "strongly agree"; answers were verbally labelled and midpoints ("neither disagree nor agree" used for attitude measures) were used for attitude measures, as suggested by Dolnicar (2013). These statements included: "I enjoy interacting with automated systems, such as Siri (Apple) or Alexa (Amazon)", "I trust such automated systems", "I think driver assistance systems, such as adaptive cruise control, lane keeping assistance, or other advanced systems, are useful", "I have used (in my own car or someone else's) such advanced driver-assistance systems". Socio-demographic questions included age, gender, household size, disability in household, education level, main occupation, household income, and current residence location (city and country), with a "prefer not to answer" option for these. As stated preference studies are susceptible to anchoring bias (McFadden, 2001), socio-demographic questions were placed at the end of the survey, so that people would not be biased in answering them according to what they think would be consistent with their choices. This can also overcome the stereotype threat (Steele, 1995) in which people try to avoid the confirmation of any stereotype they feel threatened by.

\footnotetext{
${ }^{3}$ A question consisted sometimes of a matrix including several agreement statements, focusing on one attribute for instance.
} 
In the second part, UAM was introduced by presenting some of its properties found in the pertinent literature (presented in Section 1). The assumptions for the vehicle design were mostly based on the economic model by Uber Elevate (2018) who proposed a vehicle with four seats. The process was defined as in Porsche Consulting (2018), starting with the first mile, followed by boarding, in-vehicle flight including take-off and landing, de-boarding, and finally the last mile; in this study, both boarding and de-boarding processes were estimated at around three minutes, with flight ranges of 20 to $50 \mathrm{~km}$ (for intra-city). In particular, for our study, an example of $30 \mathrm{~km}$ was given for the transfer from Munich's airport to its city center (Marienplatz).

Based on the above studies, the system was defined as a future mobility service provided by fullyautomated electrically powered vertical take-off and landing aircraft (eVTOL) with four-seat capacity (including one wheelchair seat), operating at a speed of around $150 \mathrm{~km} / \mathrm{h}$. The service would be on-demand, booked online (through the service's app or website), and passengers would have the possibility to book for up to four passengers or to ride-pool with other passengers and save money. The required boarding time was set to be 5 minutes prior to take-off, with access and egress through vertiports (helipad-like infrastructures) that would be integrated with the existing public transportation system.

Two scenarios were given to present realistic attributes of the service (trip duration and fare), starting hypothetically in 2030, with taxi as a benchmark. These targeted the region of Munich, by presenting two trips where public transportation would need more than an hour with a necessary transfer in the center, with intra-city urban ranges of 20 and $30 \mathrm{~km}$ (for the second and first examples respectively). Other modes were not presented as the aim of the survey was to understand the user adoption and not to conduct a mode choice study; scenarios therefore aimed to familiarize respondents with the system. For UAM, the access time was given as the combination of travel time to the nearest vertiport and an average waiting time of five minutes (assuming a service integrated with public transportation and a $10-$ min frequency ${ }^{4}$ ). In-vehicle travel times (including vehicle take-off and landing) were based on a travel speed approximation of $150 \mathrm{~km} / \mathrm{h}$ and the direct distance between the origins and destinations. Boarding time was approximated as the sum of both boarding and de-boarding times, assumed to be 5 minutes in total. On the other hand, taxi attributes were based on traffic conditions and a waiting time of five minutes was assumed for taxi; service scenarios are presented in Figure 1. Following this introduction, respondents were first asked to rank the given factors they believed to be the most important for adopting and using UAM. These were "booking experience", "on-time performance (reliability)", "operation characteristics (availability/frequency of service)", "process of boarding", "safety", "trip cost", "trip purpose", "trip duration", "vehicle characteristics (comfort and cleanliness)". Then, respondents' perceived usefulness of the service was assessed in a Likert-scale question with options ranging from "not at all useful" to "extremely useful".

In this second part of the survey, latent constructs affecting automation acceptance were investigated, in the form of five-point Likert scale agreement statements (ranging from "strongly disagree" to "strongly agree"), such as data concerns, trust and safety, cost perception, and the value of travel time savings. Statements on data concerns were: "I am worried that my data goes to a third party", "My fear of cybersecurity could prevent me from using UAM", "I am concerned about the loss of jobs induced by automation"; on trust and safety through UAM's operation characteristics: "Service reliability (on-time performance) is a very important feature for trusting UAM", "In order for me to feel safe, I would expect UAM's vehicles to be equipped with surveillance cameras", "I should be able to talk to an operator on the ground at any time", "The operator should be able to override the system and remotely control the UAM's vehicles in case of emergency", "The service provider's reputation is very important to gain trust to use UAM". Statements on cost perceptions included the following: "I would be willing to use the service, as long as its price is in the same range as that of a taxi", "I would first think about cost when deciding whether or not to use UAM", "I think UAM's service costs provided in the scenarios are reasonable". Finally, statements on time savings were as follows: "Travel time saving is a key factor in deciding whether or not to use UAM", "5-min 300 travel time saving is important", "10-min travel time saving is important", "20-min travel time saving is important".

Latent statements were followed by the stated preference question on adoption time horizon: "When are you most likely going to use UAM?". Alternatives included options ranking from the first year of

\footnotetext{
${ }^{4}$ Both access and egress time were based on assumptions of a $10-$ min frequency of the service.
} 
Example 1: A trip from Munich Airport to Dachau:

\begin{tabular}{|c|c|c|}
\hline & UAM & TAXI \\
\hline Trip Duration & $\begin{array}{l}\text { - } 15 \text { min access time } \\
\text { - } 5 \text { min boarding time } \\
\text { - } 13 \text { min in-vehicle travel time } \\
\text { - } 5 \text { min egress time }\end{array}$ & $\begin{array}{l}\text { - } 5 \text { min waiting time } \\
\text { - } 28-40 \text { min in-vehicle travel time }\end{array}$ \\
\hline Trip Fare & - $90 €$ & - $53-69 €$ \\
\hline
\end{tabular}

Example 2: A trip from Planegg to Taufkirchen:

\begin{tabular}{|c|c|c|}
\hline & UAM & TAXI \\
\hline Trip Duration & $\begin{array}{l}\text { - } 8 \mathrm{~min} \text { access time } \\
\text { - } 5 \mathrm{~min} \text { boarding time } \\
\text { - } 8 \mathrm{~min} \text { in-vehicle travel time } \\
\text { - } 12 \mathrm{~min} \text { egress time }\end{array}$ & $\begin{array}{l}\text { - } 5 \text { min waiting time } \\
\text { - } 30-55 \text { min in-vehicle travel time }\end{array}$ \\
\hline Trip Fare & - $53 €$ & - $40-52 €$ \\
\hline
\end{tabular}

Figure 1: Survey scenarios

operation (Y1), the second or third years of operation (Y2-Y3), the fourth or fifth years of operation (Y4Y5), starting the sixth year of its operation (Y6+), to "never" (non-adopters), and "unsure" (uncertain adopters). Respondents were also asked about the most probable trip purpose they would use UAM for, including "daily commute", "business travel", and "leisure".

The third part of the survey also aimed at revealing latent variables on the respondents' social attitudes, through similar Likert-scale constructs. The familiarity with various on-demand services (Airbnb, DriveNow/Car2Go, Uber, BlablaCar: "I am not familiar with the service" to "I use it frequently"), the use of social media platforms (Facebook, WhatsApp, Instagram, Twitter: "I don't use it" to "I use it several times a day"), the comfort with online services (online booking, banking, shopping: "very uncomfortable" to "very comfortable"), with flying (including "Prefer not to answer"), the willingness to share a ride (such as in a taxi or BlaBlaCar: "very unwilling" to "very willing") with strangers, the enjoyment of driving a car ("don't enjoy it at all" to "very much enjoy it"), and environmental awareness were investigated. The latter included five-point Likert scale agreement statements: "I am concerned about global warming", "I do not change my behavior based on environmental concerns", "I am willing to spend a bit more to buy a product that is more environmentally friendly". Respondents were also asked if they had been involved in a car crash and its severity level (if yes, between "no injuries", "minor injuries", and "major injuries"). The survey ended with a free comment field where respondents could optionally express their further concerns or suggestions.

First, a pilot survey was conducted to gain useful insights on potential biases in the survey design. The insights gained from this pilot study (in the form of comments and by evaluating preliminary models) were incorporated in the final survey, which was then published online using Limesurvey Pro (limesurvey.org). The survey was publicly available for two months starting from the 18th of July 2018 and disseminated through various channels, including Facebook, Instagram,and mailing lists (such as student lists at the Technical University of Munich).

\subsection{Descriptive analysis and model development}

A preliminary descriptive analysis was performed to understand the sample distribution and the stated adoption of different demographics. Then, models were built using exploratory factor analysis and discrete 
choice modeling (namely multinomial logit models and ordered logit models).

The exploratory factor analysis (EFA) was applied to the second and third parts of the survey pertaining to the respondents' perceptions (mostly of UAM automation) and social behaviors, respectively. This method was used to primarily identify latent constructs behind the variables and secondarily to reduce the data dimensionality. The variables mainly used were those with the same scale, such as five-point Likert scale agreement statements. In this study, EFA was applied using the maximum likelihood estimation (MLE) as a factor extraction method: factanal in the R statistical computing software (R Core Team, 2019). The suggested number of factors was obtained using the Kaiser-Guttman method (Yeomans \& Golder, 1982). Also, after trying different rotations, varimax orthogonal rotation was used (Kaiser, 1958). Factor scores were computed using factor.scores and the "component" method, a weighted sum of the factor loads.

As the answer options of the survey are discrete categories of adoption time horizon, discrete choice modeling was applied to identify and analyze the factors significantly affecting adoption (independent variables). Using pythonbiogeme (Bierlaire, 2003), both multinomial and ordered logit models were specified and estimated. As the outcomes for "Y6+" and "never" represented very small percentages of the sample size (less than 5\%), both categories were ultimately merged. Starting from multinomial logit models and based on the inputs from the factor analysis, models were developed in a stepwise fashion, first backward (from saturated models), where only variables of high significance ( $95 \%$ or $90 \%$ confidence interval) were kept, then forward (from empty models), where significant variables were added one after the other, using similar confidence levels. Both generic and alternative specific models were developed, where independent riables were specific to the different outcomes. Hypothesis testing was used in case some variables had similar estimates in order to test if merging them into generic variables would improve the overall model. Also, models were compared against each other by performing a log-likelihood test, and by assessing the values of the statistical parameters AIC and BIC. After assessing the results of the multinomial logit models (MNLs), ordered logit models (OLMs) were proposed by initially specifying models with variables that showed patterns across the outcomes (adoption time horizon), then testing them for significance like in the MNLs. After testing the model performance, the late adopters (Y6) and non-adopters (never) were merged in the proposed OLM. Despite the limitations of OLMs for the non-ordinal scale, these were used for testing the possible order of the outcomes, mostly for "unsure" respondents.

\subsection{Study limitations}

The convenience sample resulting from the online dissemination of the survey is a limitation of the sampling approach, might influence the results, and may potentially lead to a lower representativeness of the population. To overcome this, the authors conducted statistical tests to test the significance of attitudes across demographics; for instance gender, or language. These were then taken into consideration for the model development. Moreover, the assumption that factors used for the factor analysis are uncorrelated is subject to limitations; Fabrigar et al. (1999) advise instead the use of oblique correlations, and Mokhtarian et al. (2009) use it in their study to reveal correlations among factors.

Since this is a Stated Preference (SP) survey, some statements might be biased. Particularly, attitude statements may induce some prompting due to their formulation, as they lead to respondents' tendency to agree, also known as the acquiescence bias. According to Baumgartner \& Steenkamp (2001), this response bias is a threat to the validity of the questionnaire results. To overcome this, these statements were controlled for their quality, as discussed in Section 4.

Finally, most factors in our study are perception variables, only related to respondents' attitudes and not to the service attributes, which might affect the dataset variability.

\section{Data collection and results}

375 The survey generated 221 responses, with most respondents residing in Europe (181 respondents), particularly in Germany (138 or about $60 \%$ of the sample size), and specifically the region of Munich (97 respondents). The rest were scattered outside Europe between the US, Latin America, and the Middle East. Due to its high concentration and significance, the group of Munich was considered as a significant 
subsample. It should be noted that the location only represents the place of residence, and not the place of origin. The average completion time was $13.6 \mathrm{~min}$ with a standard deviation of $6.5 \mathrm{~min}$. Overall, a good representation of gender, occupation, household size, and household incomes was observed, as well as an overrepresentation of the age category 25-34 and of higher levels of education, possibly due to the online method of survey distribution. Also, public transportation as a main commute mode was overrepresented in the Munich subsample. In all cases, missing values (representing less than $5 \%$ of the sample size) were recoded using mean or median values (Tabachnick et al., 2007). The summary statistics of the entire sample and the major subsample (Munich) are presented (before further processing) in Table 1, benchmarked against the latest Munich Census for reference (Statistische Ämter des Bundes und der Länder, 2014).

Among the 221 respondents, $36.65 \%$ stated that they would adopt UAM in the second or third year of its implementation, followed by $22.17 \%$ claiming an adoption during its first year, $14.03 \%$ during its fourth and fifth year, $2.71 \%$ starting its sixth year, and $3.17 \%$ stating that they would never adopt the service. Moreover, $21.27 \%$ of the respondents expressed uncertainty ("unsure") on their adoption time horizon of UAM. The analysis of the results highlighted the importance of safety for UAM adoption as the majority of respondents (more than $50 \%$ ) ranked it as the most important factor in their intention to adopt UAM. Also, a strong indication towards the importance of UAM costs (second factor), trip duration (third factor), on-time reliability (fourth factor), and operation characteristics (fifth factor) was given. The suggested ranking was obtained by extracting for each rank (e.g.: first rank, second rank, etc.) the factor with the highest percentage of respondents. For the second to fifth ranks, the mentioned factors had a share of about $20 \%$ of the respondents. On the other hand, vehicle characteristics, boarding process, booking experience, and trip purpose were ranked as sixth to ninth factor by most of the respondents, gathering each also about $20 \%$ of the respondents. 
Table 1: Summary of sample and subsample characteristics

\begin{tabular}{|c|c|c|c|c|}
\hline & & $\begin{array}{l}\text { Total sample } \\
\qquad(\mathrm{N}=221)\end{array}$ & $\begin{array}{l}\text { Munich subsample } \\
\qquad(\mathrm{N}=97)\end{array}$ & $\begin{array}{c}\text { Munich Census } \\
(2011)\end{array}$ \\
\hline \multirow[t]{3}{*}{ Gender } & Female & $43.0 \%$ & $51.6 \%$ & $48.6 \%$ \\
\hline & Male & $56.1 \%$ & $47.4 \%$ & $51.4 \%$ \\
\hline & $\begin{array}{l}\text { Prefer not to an- } \\
\text { swer }\end{array}$ & $0.9 \%$ & $1.0 \%$ & - \\
\hline \multirow[t]{7}{*}{$\operatorname{Age}^{\mathrm{a}}$} & $0-17$ & $0.5 \%$ & - & - \\
\hline & $18-24$ & $19.5 \%$ & $23.7 \%$ & $9.2 \%$ \\
\hline & $25-34$ & $45.7 \%$ & $56.7 \%$ & $21.7 \%$ \\
\hline & $35-44$ & $19.0 \%$ & $16.5 \%$ & $22.4 \%$ \\
\hline & $45-54$ & $9.5 \%$ & $16.5 \%$ & $22.2 \%$ \\
\hline & $55-64$ & $5.0 \%$ & - & $16.8 \%$ \\
\hline & $65+$ & $0.9 \%$ & - & $7.7 \%$ \\
\hline \multirow[t]{7}{*}{ Main occupation } & Full-time employed & $57.9 \%$ & $46 \%$ & $87.1 \%$ \\
\hline & Part-time employed & $9.1 \%$ & $8 \%$ & \\
\hline & Student & $28.1 \%$ & $42 \%$ & $2.9 \%$ \\
\hline & Unemployed & $0.5 \%$ & $1 \%$ & $2.2 \%$ \\
\hline & Self-employed & $2.3 \%$ & $1 \%$ & $7.8 \%$ \\
\hline & Retired & $0.9 \%$ & - & \\
\hline & $\begin{array}{l}\text { Prefer not to an- } \\
\text { swer }\end{array}$ & $1.4 \%$ & $1 \%$ & - \\
\hline \multirow[t]{6}{*}{ Education } & High School & $8.6 \%$ & $6 \%$ & $34.1 \%$ \\
\hline & Apprenticeship & $2.7 \%$ & $1 \%$ & $40.7 \%$ \\
\hline & Bachelor & $26.7 \%$ & $26 \%$ & $22.7 \%$ \\
\hline & Master & $47.5 \%$ & $52 \%$ & \\
\hline & Doctorate & $13.1 \%$ & $13 \%$ & $2.5 \%$ \\
\hline & $\begin{array}{l}\text { Prefer not to an- } \\
\text { swer }\end{array}$ & $1.4 \%$ & $2 \%$ & - \\
\hline \multirow[t]{10}{*}{ Household income $^{b}$} & $<500 €$ & $7.2 \%$ & $13.4 \%$ & \\
\hline & $500-1000 €$ & $8.6 \%$ & $13.4 \%$ & \\
\hline & $1000-2000 €$ & $11.3 \%$ & $10.3 \%$ & \\
\hline & $2000-3000 €$ & $14.0 \%$ & $16.5 \%$ & \\
\hline & $3000-4000 €$ & $10.9 \%$ & $6.2 \%$ & \\
\hline & $4000-5000 €$ & $10.9 \%$ & $7.2 \%$ & \\
\hline & $5000-6000 €$ & $4.9 \%$ & $3.1 \%$ & \\
\hline & $6000-7000 €$ & $5.4 \%$ & $30.9 \%$ & \\
\hline & $>7000 €$ & $6.3 \%$ & $21.7 \%$ & \\
\hline & $\begin{array}{l}\text { Prefer not to an- } \\
\text { swer }\end{array}$ & $20.4 \%$ & $3.1 \%$ & \\
\hline \multirow{6}{*}{$\begin{array}{l}\text { Main commute }{ }^{\mathrm{c}} \\
\text { mode }\end{array}$} & Car as a driver & $33.9 \%$ & $14.0 \%$ & $31.0 \%$ \\
\hline & Car as a passenger & $1.8 \%$ & - & \\
\hline & $\begin{array}{l}\text { Public transporta- } \\
\text { tion }\end{array}$ & $40.7 \%$ & $63.0 \%$ & $28.8 \%$ \\
\hline & Bike & $15.4 \%$ & $20.0 \%$ & $14.7 \%$ \\
\hline & Walk & $5.9 \%$ & $1.0 \%$ & $25.5 \%$ \\
\hline & Other & $2.3 \%$ & $2.0 \%$ & - \\
\hline
\end{tabular}

a Census values for age are based on different age categories and are therefore best-fit values for the survey classes.

b There are no census values for income levels; however the average disposable household income for the year 2016 is $4220 €$ (Euromonitor International, 2017).

c The given values are trip distribution percentages (MVG 2011). 
A preliminary analysis of the attitudes of different demographics showed the importance of these factors for the adoption intention. This was mostly observable for gender, main occupation, education, survey language, and previous crashes, as observed in Figure 2. Females were found to have a lower tendency of being immediate adopters (Y1), and a higher of being "unsure" about their adoption time; as expressed by the $12 \%$ of female respondents for Y1 compared to $30 \%$ for their male counterparts. For the main occupation, respondents working full-time expressed a higher immediate adoption intention (30\%) compared with parttime employees $(0 \%)$, or students $(14 \%)$, which can be due to higher income levels and/or higher value of time. The survey language also seemed to impact stated adoption. Respondents who filled the survey in English showed a higher interest in early adoption (31\%) and less skepticism (12\%) compared to those filling the survey in German. Respondents with previous crashes and no injuries expressed a higher intention of immediate adoption (26\%) compared to those who had injuries. Respondents with different education levels also stated different preferences: those with lower levels of education (bachelor or lower) expressed less uncertainty (19\%) compared to the ones with higher levels of education (doctorate). On the other hand, the latter group showed a higher interest in immediate adoption (26\%) compared to the former (18\%). Of course some of these comparisons are limited to their statistical significance, since the compared outcomes were not well represented for all categories, such as occupation, crash history, and education levels. On the other hand, gender and survey language were rather well distributed.

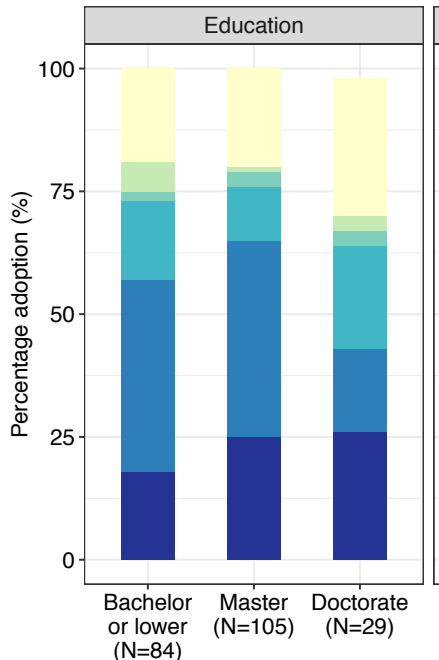

$(\mathrm{N}=84)$

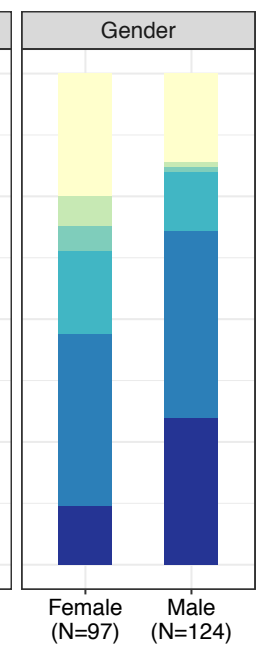

$(\mathrm{N}=97) \quad(\mathrm{N}=124)$

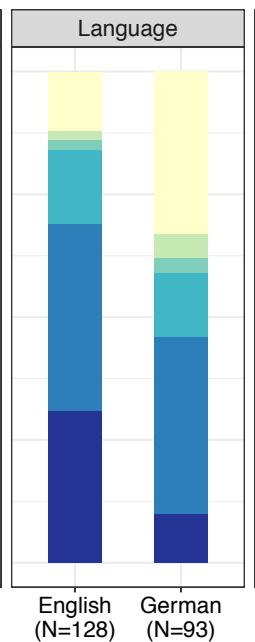

$(\mathrm{N}=128) \quad(\mathrm{N}=93)$

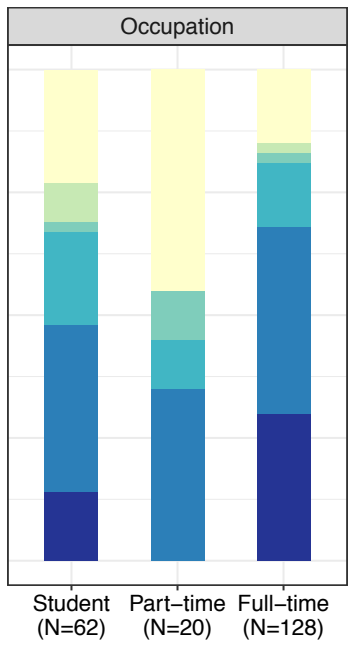

$(\mathrm{N}=62) \quad(\mathrm{N}=20) \quad(\mathrm{N}=128)$

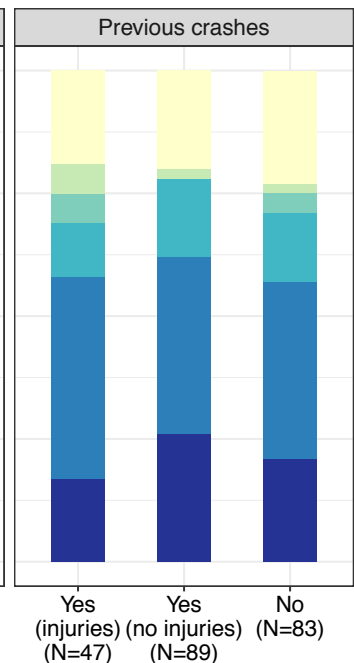

$(\mathrm{N}=47) \quad(\mathrm{N}=89)$

\begin{tabular}{l|l|l|l|l|l} 
Stated time adoption & Y1 & Y2-Y3 & Y4-Y5 & Y6+ & Never
\end{tabular}

Figure 2: UAM adoption by different demographics

The exploration of respondents' attitudes, based on the Likert scale statements, showed that gender and survey language were the demographics where most differences were observed. As presented in Figure 3, females seemed to give a higher level of importance to the loss of jobs due to automation as well as to safety; the latter is demonstrated by higher safety camera expectations and requirements for an operator on the ground and to override the vehicle in case of emergency. On the other hand, male respondents seemed to have more flying comfort than their female counterparts. These findings are statistically significant (error bars in Figure 3 drawn based on the standard error) and compatible with those from the literature; in particular the study by Hohenberger et al. (2016), where women were found to have a lower intention to use autonomous vehicles, possibly due to the effect of gender on anxiety, rather than on pleasure.

Different attitudes were observed based on the survey language. Notably, the respondents filling the survey in English expressed a higher trust in automation, enjoyment of automation, perceived usefulness of ADAS, and of UAM, compared to those filling the survey in German. A similar, less remarkable, pattern was 
observed for respondents residing in Munich as opposed to those who don't. This finding parallels the results of the study on Autonomous Vehicles Readiness, where Germany was ranked 12th in consumer acceptance, despite being third in technology and innovation (KPMG, 2018): it can be assumed that language reflects better the culture than the place of residence.

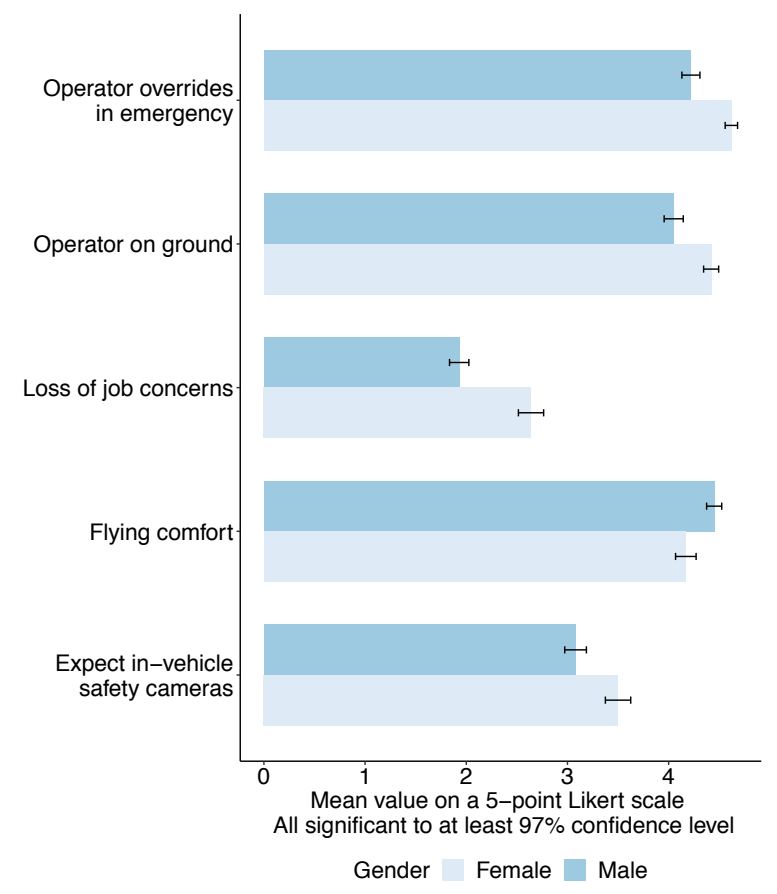

(a)

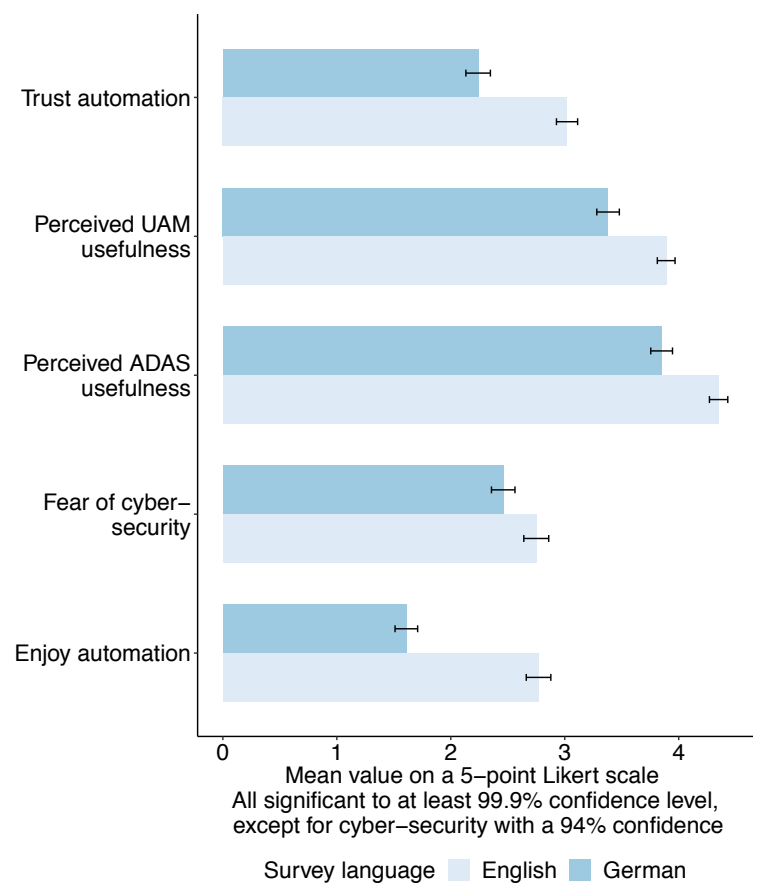

(b)

Figure 3: Attitudes towards different statements: (a) by gender; and (b) by language

Attitude statements from the second and third parts of the survey (see Section 3.1) were also analyzed to assess the quality of the responses. After a careful examination of the distribution of the answers across the Likert-scale ("strongly disagree" to "strongly agree"), two statements were identified as prompted. This was observed for the agreement statements on the necessity of an operator to override the vehicle in case of emergency, and on the importance of the service provider's reputation to gain trust to use UAM. For both statements, the respondents' tendency to agree, also known as the acquiescence bias, was noted, as mentioned in the study limitations (see Section 3.3). Accordingly, both statements were removed from the subsequent analysis and model specifications.

Finally, a qualitative analysis of the comments left at the end of the survey showed additional concerns of the respondents. The biggest concern was expressed by eight respondents on environmental impacts, including concerns from noise and visual pollution (four respondents for each). For the latter, the respondents expressed the disturbance they would feel from being watched from above ("Not in My Backyard" effect, as described by one respondent). Two respondents expressed their concerns about privacy (concerning data sharing) and safety (one of them stated the desire to wait for an incident-free operation of UAM). Moreover, three respondents expressed their concern of economic impacts of UAM; one of them was concerned that the service would target a niche market. Also, two respondents expressed their desire for a system integration of UAM (with the existing and future transportation systems), one respondent was interested in the information sharing inside the vehicle, another for a high frequency service with on-demand availability, and finally one more about the use case or purpose of UAM. 


\section{Model development and estimation}

This section describes the model development, starting from exploratory factor analysis and continuing

\subsection{Exploratory factor analysis}

The outcome of the exploratory factor analysis for respondents' perceptions on automation is presented in Table 2. Four factors were eventually extracted, explaining a cumulative variance of $52 \%$ of the total variance. As observed in Table 2, each factor explains more than $10 \%$ of the total variance (with the exception of one that explains $9 \%^{5}$ ), which is considered acceptable according to Costello \& Osborne (2005). This is compatible with the work of several researchers who used factor analysis to understand users' perceptions of transportation systems (Tyrinopoulos \& Antoniou, 2008; Efthymiou et al., 2013), reducing the initial indicators to fewer factors each explaining more than $10 \%$ of the total variance (with one exception at most), with a cumulative total variance ranging roughly from an average of $46 \%$ to $50 \%$. Loadings lower than 0.4 are not shown to simplify the table.

By looking at the latent meaning that these variables might have, the factors are interpreted as follows. The value of time savings is a cluster of the three variables on the perception of saving 5,10 , and 20 min of travel time. The enjoyment of automation ${ }^{6}$, trust of automation, and perceived usefulness of UAM are interpreted as the affinity to automation. The fear of cyber-security, the concern of data being shared to a third party, and the concern of loss of jobs due to automation are grouped under data and ethical concerns. Finally, the need for an operator on the ground, and of in-vehicle safety cameras are interpreted as safety concerns.

Table 2: Factor analysis on respondents' perceptions

\begin{tabular}{lcccc}
\hline Loadings & Factor 1 & Factor 2 & Factor 3 & Factor 4 \\
\hline Travel time savings 5min & 0.78 & & & \\
Travel time savings 10min & 0.98 & & \\
Travel time savings 20min & 0.59 & & \\
Enjoy automation & & 0.80 & \\
Trust automation & & 0.75 & \\
UAM is useful & & 0.51 & & \\
Fear of cyber-security & & & 0.70 & \\
Fear that data goes to a third party & & & 0.53 & \\
Loss of job concerns & & & & 0.49 \\
Operator on the ground & 2.01 & 1.66 & 1.14 & 0.67 \\
In-vehicle safety cameras & 0.18 & 0.15 & 0.10 & 0.96 \\
\hline Sum of square of loadings & 0.18 & 0.33 & 0.44 & 0.52 \\
Proportion variance & Value of & Affinity to & Data and & Safety \\
Cumulative variance & time savings & automation & ethical concerns & concerns \\
\hline Factor interpretation & & &
\end{tabular}

For respondents' social attitudes, four factors were extracted, explaining a cumulative variance of $55 \%$ of the total variance, presented in Table 3. Variables pertaining to social attitudes were grouped under affinity to online services, environmental awareness, affinity to social media, and affinity to sharing, with all factors explaining at least $10 \%$ of the a variance and therefore also considered acceptable (Costello \& Osborne, 2005).

\footnotetext{
${ }^{5}$ This factor was retained due to its high explanatory power and interpretability.

${ }^{6}$ Enjoyment of automated systems like Alexa or Siri
} 
Table 3: Factor analysis on respondents' social attitudes and behaviors

\begin{tabular}{|c|c|c|c|c|}
\hline Loadings & Factor 1 & Factor 2 & Factor 3 & Factor 4 \\
\hline Online booking & 0.81 & & & \\
\hline Online banking & 0.86 & & & \\
\hline Online shopping & 0.65 & & & \\
\hline Concerned about global warming & & 0.99 & & \\
\hline Spend on environmental products & & 0.5 & & \\
\hline Instagram & & & 0.99 & \\
\hline Facebook & & & 0.43 & \\
\hline BlaBlaCar & & & & 0.67 \\
\hline Airbnb & & & & 0.5 \\
\hline Willingness to share & & & & 0.5 \\
\hline Sum of square of loadings & 1.93 & 1.28 & 1.24 & 1.06 \\
\hline Proportion variance & 0.19 & 0.13 & 0.12 & 0.11 \\
\hline Cumulative variance & 0.19 & 0.32 & 0.45 & 0.55 \\
\hline Factor interpretation & $\begin{array}{c}\text { Affinity to } \\
\text { online services }\end{array}$ & $\begin{array}{c}\text { Environmental } \\
\text { awareness }\end{array}$ & $\begin{array}{l}\text { Affinity to } \\
\text { social media }\end{array}$ & $\begin{array}{l}\text { Affinity to } \\
\text { sharing }\end{array}$ \\
\hline
\end{tabular}

The factor analysis interpretation (Tables 1 and 2) is similar to the one on shoppers' attitudes by Mokhtarian et al. (2009), where a factor analysis was applied to 42 attitude agreement statements (fivepro-environment, technology; these are comparable to the presented factors: affinity to automation, time savings, safety concerns, affinity to online services and social media, environmental awareness, and affinity to automation and social media, respectively.

\subsection{Multinomial logit model}

Aiming at a better understanding with regards to the factors which affect adoption, a multinomial logit model was estimated; the model specification and estimation results are shown in Table 4 . The coefficient estimates were in general reasonable in sign and magnitude and consistent with prior expectations; most of them significant at least to the $95 \%$ confidence level with a t-value higher than 1.96 , with a couple being significant to the $90 \%$ with a t-value higher than 1.65. For instance, estimates for the affinity to automation were highly significant and positive mostly for early adoption (estimate of 1.15 for Y1), but also (to a lesser extent) for later years (estimate of 0.79 for Y2-Y5). For most of the respondents (Y1-Y5 and unsure), highly significant and positive impacts were also noted for the affinity to social media and to WhatsApp (estimate coefficients of 0.50 and 0.53 , respectively); the same impact was observed for full-time employment (estimate of 0.63 for Y1-Y3). Cost factors also had a significant positive impact on adoption. Scaling UAM prices to taxis' highly contributed to immediate adoption (estimate of 0.32 for Y1). On the other hand, higher data and ethical concerns (including fear of cyber-security, concerns of data being passed to third parties, and loss of job concerns) had influential negative impacts on early adoption (-0.24 for Y1). Previous crash experiences also had a negative impact on adoption in general, with lesser impacts on later adoption (estimate of -2.42 for Y1, compared to -1.89 for Y2-Y5). Safety concerns (including the importance of having an operator on the ground at any time and of in-vehicle safety cameras) also negatively affected adoption (estimate of -0.34) with a high influence on immediate adoption (Y1) and later adoption (Y4-Y5). Female respondents were in general less likely than their male counterparts to adopt UAM (estimate of -2.94 for all years) and highly educated respondents (doctorate level or higher) less likely to adopt it in its early years (estimate of -1.43 for Y2-Y3). Moreover, German as a survey language (compared to English) was highly correlated with uncertainty (estimate of 1.42). Furthermore, higher income level respondents were less likely to be late adopters of UAM (estimate of -1.42 for Y4-Y5). The perception of travel time importance was also decisive in UAM adoption for the second and third years (estimate of 0.28 for Y2-Y3) and the value of time savings (including the perception of each of 5,10, and 20 minutes of time savings) for later adoption 
(estimate of 0.33 for Y4-Y5). Finally, public transport commuters were more likely to adopt UAM during its later years (estimate of 0.85 for $\mathrm{Y} 4-\mathrm{Y} 5$ ) and the alternative-specific constant for respondents stating a very late or non-adoption (Y6+, Never) was positive and highly significant (estimate of 6.73).

Table 4: Multinomial logit model results $(\mathrm{N}=221)$

\begin{tabular}{lrrr} 
Parameters & estimate & std. error & t-stat \\
\hline ASC Y6+ or never & 6.73 & 2.20 & 3.06 \\
Affinity to automation Y1 & 1.15 & 0.32 & 3.59 \\
Affinity to automation Y2-Y5 and unsure & 0.79 & 0.31 & 2.60 \\
Cost as taxi Y1 & 0.32 & 0.18 & 1.83 \\
Previous crash with injuries Y1 & -2.42 & 0.97 & -2.49 \\
Previous crash with injuries Y2-Y5, unsure & -1.89 & 0.86 & -2.20 \\
Starting language German unsure & 1.42 & 0.34 & 4.13 \\
Data concerns Y1 & -0.24 & 0.12 & -1.98 \\
Doctorate level of education Y2-Y3 & -1.43 & 0.53 & -2.67 \\
Female Y1-Y5 and unsure & -2.94 & 1.14 & -2.58 \\
Full-time employment Y1-Y3 & 0.63 & 0.31 & 2.09 \\
High income: 3000-7000 Euro Y4-Y5 & -1.42 & 0.65 & -2.20 \\
PT commute Y4-Y5 & 0.85 & 0.40 & 2.11 \\
Safety concerns Y1 and Y4-Y5 & -0.34 & 0.10 & -3.46 \\
Affinity to social media Y1-Y5 and unsure & 0.50 & 0.29 & 1.71 \\
TT important for UAM Y2-Y3 & 0.28 & 0.07 & 3.81 \\
Value of time savings Y4-Y5 & 0.33 & 0.08 & 4.07 \\
Affinity to WhatsApp Y1-Y5 and unsure & 0.53 & 0.26 & 2.07 \\
\hline Summary statistics & & & \\
$\bar{\rho}^{2}$ & 0.23 & & \\
AIC & 546.42 & & \\
BIC & 607.587 & & \\
\hline
\end{tabular}

\subsection{Ordered logit model}

Ordered logit models were also built with adoption time horizon as a dependent variable. Although time frame can theoretically be ordered from the first to the sixth or more years (even never), the category "unsure" cannot be ranked in that scale. Therefore, based on previously observed patterns in the MNL model, OLMs were proposed. For instance, the affinity to automation estimate from the MNL (Table 4) was positive and strongly significant (more than 95\%) for both immediate adoption (Y1) and later adopters (Y2 to Y5) and unsure respondents; however, the impact was higher for immediate adopters (Y1), expressed by the higher coefficient estimate (1.15 compared to 0.79). Similarly, previous crashes with injuries negatively impacted adoption, expressed by strongly significant (more than 95\%) and negative coefficient estimates; higher even for Y1 (-2.42 compared to -1.89 for the rest). These for instance guided the specification of an ordered logit model, where such attributes would be ranked, as suggested by the patterns in the MNL. Accordingly, two cases were proposed. In the first case, the ordered categories were as follows: Y1; Y2-Y3; Y4-Y5; Unsure; Y6+/Never. The second case was built from the first by merging the "unsure" category with the one of late and non-adopters. The corresponding categories were therefore: Y1; Y2-Y3; Y4-Y5; Unsure, Y6+ and Never.

Table 5 represents the final OLM model for both cases. The highly significant cut values for case 1 indicate that adoption is indeed ordered and people who are unsure display a behavior that is ranked between late (Y4-Y5) and extremely late or non-adopters (Y6+ or Never). This was rather expected from the patterns observed in MNL models. The significant parameters are the same for both cases: affinity to automation, full-time employment, and cost as taxi (meaning the willingness to use the service for prices in the range of taxis) are associated with an early adoption. On the other hand, data and ethical concerns and starting language German are strongly correlated with a later adoption. 
Table 5: Ordered logit models results $(\mathrm{N}=221)$

\begin{tabular}{|c|c|c|c|c|c|c|}
\hline \multirow[b]{2}{*}{ Parameters } & \multicolumn{3}{|c|}{ Case 1} & \multicolumn{3}{|c|}{ Case 2} \\
\hline & estimate & std. error & $t$-stat & estimate & std. error & $t$-stat \\
\hline Affinity to automation & -0.26 & 0.07 & -3.54 & -0.23 & 0.07 & -3.11 \\
\hline Cost as taxi & -0.37 & 0.13 & -2.82 & -0.38 & 0.14 & -2.70 \\
\hline Starting language German & 0.61 & 0.30 & 2.05 & 0.70 & 0.30 & 2.32 \\
\hline Data and ethical concerns & 0.27 & 0.08 & 3.32 & 0.26 & 0.08 & 3.19 \\
\hline Full-time employment & -0.96 & 0.26 & -3.68 & -1.03 & 0.27 & -3.84 \\
\hline \multicolumn{7}{|l|}{ Intercepts } \\
\hline \multicolumn{7}{|l|}{ Case 1} \\
\hline $\mathrm{Y} 1-\mathrm{Y} 2-\mathrm{Y} 3$ & -4.22 & 0.85 & -4.97 & & & \\
\hline $\mathrm{Y} 2-\mathrm{Y} 3-\mathrm{Y} 4-\mathrm{Y} 5$ & -2.16 & 0.21 & 9.96 & & & \\
\hline Y4-Y5-Unsure & -1.36 & 0.14 & 5.93 & & & \\
\hline Unsure-Y6+/Never & 0.87 & 0.31 & 7.10 & & & \\
\hline \multicolumn{7}{|l|}{ Case 2} \\
\hline $\mathrm{Y} 1-\mathrm{Y} 2-\mathrm{Y} 3$ & & & & -4.02 & 0.88 & -4.57 \\
\hline $\mathrm{Y} 2-\mathrm{Y} 3-\mathrm{Y} 4-\mathrm{Y} 5$ & & & & -1.96 & 0.21 & 9.92 \\
\hline Y4-Y5-Unsure/Y6+/Never & & & & -1.15 & 0.14 & 5.93 \\
\hline \multicolumn{7}{|l|}{ Summary statistics } \\
\hline $\bar{\rho}^{2}$ & 0.25 & & & 0.26 & & \\
\hline $\mathrm{AIC}$ & 585.10 & & & 526.04 & & \\
\hline $\mathrm{BIC}$ & 615.69 & & & 553.23 & & \\
\hline
\end{tabular}

Compared to Case 1, Case 2 presents similar values for the relevant parameters with close estimates categories and indicates that uncertain respondents can be merged with very late (Y6+) and non-adopters. In other terms, respondents showing some skepticism regarding their adoption time horizon of UAM are more likely to use it at a later stage, or not to use it at all. In both cases, uncertain adopters are associated with rather late adoption; the only difference is that one case considers uncertainty as part of non-adoption and (since the first case provides five outcomes for the dependent variable compared to four in the second), a likelihood ratio test is not possible. Therefore as both models have more or less the same meaning, deciding on the number of ordered categories depends on personal judgment and preference: parsimony vs. richness.

\section{Discussion}

\subsection{Summary findings}

Despite high stated adoption rates for UAM (about 37\% for Y2-Y3 and $22 \%$ for Y1), a non-negligible number of respondents expressed their uncertainty about their intention to use the service, as shown by the percentage of "unsure" respondents (more than $22 \%$ ). The analysis of the responses showed that safety was perceived as the factor of highest importance in using UAM (ranked by the majority of respondents as the first factor in UAM adoption). A high indication for the importance of trip cost, trip duration, service reliability and operation characteristics was also observed, as they were mostly ranked as second, third, fourth, and fifth most important factors for UAM adoption. The survey statistics indicated a high impact of socio-demographic factors on adoption and attitudes. Females expressed a much lower interest in immediate UAM adoption, expressing overall lower trust and perceived usefulness of automation, and greater security and safety concerns and expectations, expressing a higher desire for operators on the ground, and of in-vehicle safety cameras, as reflected in the mean values of the attitude Likert-scale questions (partially presented in Figure 3). On the other hand, both fully-employed and higher income respondents expressed a greater interest in early adoption, as discussed in the survey statistics (Section 4.1). Cultural impact was 
observed through the survey language, which seemed to also have an impact on automation; respondents 560 filling the survey in German expressed a lower interest in early adoption and a higher skepticism observed through a higher degree of uncertainty. This is interesting when compared to the impact of the place of residence (Munich or Germany), which was less influential than the survey language, as only the latter was a significant variable in the adoption models (MNL and OLM).

The discussed findings from the statistics were confirmed by the specified models. For instance, MNLs demonstrated the high impact of gender (female), employment (full-time), language (German language), income levels on adoption. The MNLs also showed that public transportation users were more likely to be late UAM adopters, as expressed by the positive and significant coefficient estimate for PT commuters (Table 4). Moreover, respondents with previous crash experiences with injuries were less likely to be immediate adopters, as revealed by the model finding estimates (Table 4). Safety concerns were also found to play an inhibiting role in early and late adoption, expressed by the negative and highly significant (more than $99.9 \%$ ) coefficient estimate in the MNL. These included the need for in-vehicle surveillance cameras, and for an operator on the ground at any time (resulting from the factor analysis in Table 2). Lack of safety may hinder UAM, and lead to late UAM adoption. Moreover, the affinity to automation was found crucial for UAM adoption (as demonstrated by the positive coefficients for the MNL, higher still for Y1 than for Y4-Y5, and negative for the OLM, proving as well the higher effect on immediate adoption of the affinity to automation) and included the enjoyment and trust of automation, and the perceived usefulness of UAM. Furthermore, the value of time savings and perceived costs were highly influential for late UAM adoption. As some of these findings might be counter-intuitive, their occurrence might be due to respondents' prior expectations and judgments of service properties. For instance, respondents may be skeptical about actual time savings and therefore as they value this factor, they might decide to adopt UAM later on, waiting for the service to improve its performance. This was also observed for respondents who are highly sensitive to costs as they might believe that costs would decrease a few years after the service implementation to be in the range of taxis. Moreover, higher safety concerns were negatively associated with late adoption, possibly due to the users' beliefs that safety would only need a few years to be demonstrated; waiting for too long would therefore not be needed. Also, data and ethical concerns were found to be hindering immediate adoption; this could refer to the respondents who are rather worried about their data being shared to third parties, and who tend to be uncertain about the future as they are concerned from cyber-security threats and/or the loss of jobs due to automation. Finally, the impact of social media and WhatsApp was found to be positive on adoption.

OLMs confirmed some of these factors found in the MNLs, notably the cost range importance (comparable to the taxi range for early adoption), the cultural impact (correlation between German language and later adoption), the data and ethical concerns (associated with later adoption and including the fear of cybersecurity, data sharing, and the loss of job concerns), the affinity to automation, and the employment impact. Finally, the ordered models gave meaningful insights regarding "unsure" respondents, in which these were found to have similar or close (one degree less) behavioral intentions to late adopters.

When comparing the results of this study with the reports commissioned by NASA and presented in Section 2.1, parallel findings were observed. The study by Crown Consulting (NASA, 2019) mentioned that nearly half of the consumers were potentially comfortable with delivery and UAM use cases, which is quite comparable with our results (more than 50\% stated time adoption within the first three years of implementation). Moreover, common factors were observed such as safety, privacy, loss of jobs concerns, environmental concerns, and noise and visual pollution that were extracted from our qualitative analysis. Common results were also shared with the study by Booz Allen Hamilton (NASA, 2018), particularly for user concerns like safety, privacy and noise, piloted aircraft and flight attendant, cybersecurity, cost and convenience, and gender impact with men being more comfortable and willing to use UAM; in our study 605 however, the system was assumed to be fully automated, and therefore a flight attendant was not mentioned. Instead, the importance of having an operator (available on the ground and/or remotely control the vehicle in case of emergency) was investigated. 


\subsection{Technology Acceptance Model for Disruptive Transport Technologies}

The model findings pertaining to acceptance were incorporated to extend the Technology Acceptance Model for the application of urban air mobility, and more generally disruptive transport technologies (Figure 4). Compared to the initial TAM by Davis et al. (1989), the model retains only one of the two main constructs: the perceived usefulness (PU), which directly impacts the behavioral intention (BI). The perceived ease of use (PEU; in the case of urban air mobility: service booking or boarding) was not found influential and was therefore removed from the model. More generally, for fully-automated systems, the user is not expected to do any effort. Actual system use is also omitted, as there is no way to measure it for non-existing systems. The attitude towards using the system is removed; instead the following factors (including PU) are considered as attitudes directly impacting the behavioral intention: perceived usefulness, social behavior (social attitudes related to social media use, environmental concerns, etc.), value of time (the value given to time savings), perceived costs (cost perceptions: cost range), data and ethical concerns (fear of data sharing to a third party, fear of cyber-security, and the loss of job concerns). These factors result from the estimated multinomial logit models (MNLs); data and ethical concerns and cost perceptions also result from the ordered logit models (OLMs).

The construct of trust is added as a main construct in this model, as suggested by the Automation Acceptance Model (AAM) by Ghazizadeh et al. (2012). Additionally, the proposed model introduces factors directly and positively impacting trust. These are the perceived reliability of automation, the perceived vehicle's safety, the perceived locus of control, and the previous experience with automation. The vehicle's safety and perceived locus of control are supported by the MNLs and refer to the safety from in-vehicle safety cameras and the locus of control confirmed by the importance given to the human factor (operator on the ground at any time). Moreover, both service reliability and automation experience were found from analyzing respondents' attitudes. Finally, external variables, similarly to the AAM directly impact trust, but not PU. These are given as socio-demographics and affinity to automation. The former includes gender, education, occupation, income, cultural impact (demonstrated by the survey language). In the proposed model, these external variables directly impact behavioral intention as well.

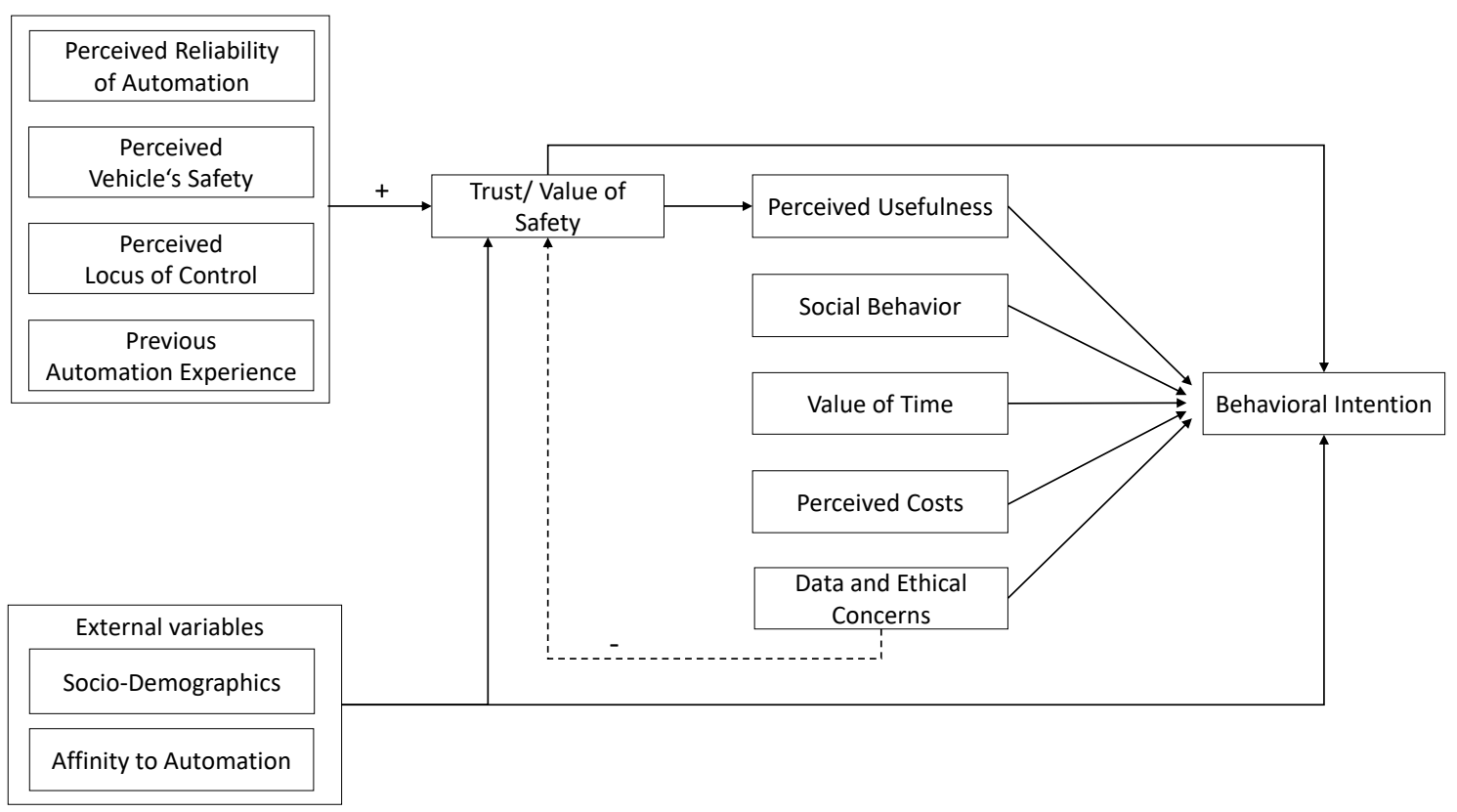

Figure 4: Technology Acceptance Model for Disruptive Transport Technologies, adapted from the original TAM by Davis et al. (1989) and the Automation Acceptance Model (AAM) by Ghazizadeh et al. (2012) 


\subsection{Insights for policymakers and industrial stakeholders}

holder engagement, to ensure a smooth urban air mobility implementation and integration with the existing transport systems. Recommendations on such areas can be summarized in the following points.

\subsubsection{Insights for policymakers}

\section{- Safety concerns}

As highlighted in the proposed Technology Acceptance Model, trust or the value of safety is a crucial component in users' adoption of urban air mobility and is determined by several components. Among these, the perception of automation reliability, vehicle's safety and locus of control are areas where stringent regulations could improve users' trust and reduce skepticism resulting from missing or erroneous information. Accordingly, safety standards enforced by the responsible authorities could ensure users' trust, alleviating negative perceptions on automation reliability and service performance. Enforcing regulations acting upon in-vehicle safety, such as the presence of in-vehicle surveillance cameras, might help increasing trust and feeling of safety. Finally, regulations focusing on the human factor in the operation of urban air mobility could take into consideration the importance of the availability (at any time) of an operator on the ground, to increase the users' perceived locus of control, and thereby trust and safety towards the service.

- Data concerns

The proposed TAM also highlights the importance of data and ethical concerns for UAM adoption, and their negative impacts on safety perception. These include concerns from information sharing to third parties, from cyber-security, and from the loss of jobs due to automation, as shown by the exploratory factor analysis results. Responsible policymaking in the area of data sharing and protection would probably ensure a higher sense of privacy for the users. For ground Autonomous Vehicles, Fagnant \& Kockelman (2015) recommend the creation of nationally recognized licensing framework for autonomous vehicles (ground), determining appropriate standards for liability, security, and data privacy. Such frameworks could be appropriately developed and transferred to urban air mobility.

- Other concerns

Not directly stemming from the models, environmental concerns expressed by respondents demonstrate the need for policy-making in the area of noise and visual impact. Regulating the allowed noise levels and flying altitudes of the vehicles could address community acceptance of both users, and non-users of urban air mobility. Moreover, an inclusive and integrated system, as defined by our study should ensure a proper integration of UAM services with existing transportation systems.

\subsubsection{Insights for industrial stakeholders}

- Service attributes

The proposed TAM revealed the importance of service attributes, i.e. cost and time, for the adoption of urban air mobility. If the system aims to attract a wider public, user requirements must be prioritized, notably pricing schemes must be defined, and regulated by the authorities, so that the service would not only be a niche market. These for instance need to be within a certain reasonable range, i.e. taxi prices, allowing competition with existing ground vehicles. Similarly, the time from access to egress (to and from the vertiports) must be optimized: a smoother process must enable an efficient process for the service to be accepted; again, if the service aims to be integrated with the existing systems, this can only be done through a proper stakeholder engagement with the responsible authorities. Finally,

a higher transparency on both time and costs of the service would ensure a higher awareness on the service attributes, which is crucial for users' perceptions towards it.

- Socio-demographics

For an inclusive service, industrial stakeholders should consider the importance of socio-demographics in the perception of the service. User categories with different gender or cultural background could be 
targeted according to their specific needs. Incentives might as well help some respondents to overcome their fears of automation.

\section{Conclusions}

In this paper, users' acceptance and adoption of urban air mobility was assessed by analyzing an online residents. Using mostly factors from the literature on the acceptance of both technology and automation (notably autonomous vehicles), and by projecting them to UAM, the survey aimed at uncovering many hypotheses on this new mobility service and thereby also validated an extended technology acceptance model for an urban air mobility context. The analysis of the survey data highlighted the importance many variables were clustered into groups having a high explanatory power and thus reducing the dataset dimensionality. These included the affinity to automation, safety concerns, data and ethical concerns, the value of time savings, in addition to social attitudes such as environmental awareness, the affinity to social media, online services, and sharing. Using the inputs from the factor analysis, significant multinomial and 作 considered as a theoretical contribution to the use case of ordered logit models with a non-conventional ordinal dependent time variable (including non-ordinal parameters such as "unsure" and "never"). Mostly, the influence of socio-demographics, cultural impact, affinity to automation (including the enjoyment and trust of automation) were shown. Trust and safety were found to be key components for UAM adoption; in particular, the presence of in-vehicle cameras and operators, as well as performance expectancy in terms of service reliability and on-time performance were noted. Data and ethical concerns, the value of time savings and costs, social attitudes including a high affinity to social media were also found as highly influential for UAM adoption. Finally, public transportation as a commute mode was found to be rather related to late adoption.

Overall, the study extracted relevant and highly significant factors, extending accordingly the TAM model for UAM use, and contributing in filling the gap in research on this new service. The findings of this work have strong insights for policymakers. Regulatory bodies should have departments targeting UAM regulations and work closely with other countries to have some unified standards; for instance, a unified European framework on suggested safety standards and allowed noise levels.

Most factors in the developed models are related to the perception and attitudes of respondents, and not to the service attributes; newer models could therefore be developed with alternative-specific variables. Scenarios could for instance present travel times or costs for different time frames. Future work could therefore focus on uncertainties pertaining to the service attributes and business models. Another research motivation could be to build a nested ordered logit model with one or more ordered nests; one of the nests could comprise uncertain or non-adopters and the other the certain adopters including the ordered (time) adoption categories. Other studies could test the developed UAM TAM by applying a confirmatory factor analysis (CFA) and developing a hybrid latent class model, in which both analysis methods (factor analysis and choice models) would be combined.

\section{Acknowledgements}

This work has been partly funded by the Bavarian Ministry of Economic Affairs, Regional Development and Energy through the OBUAM project.

\section{References}

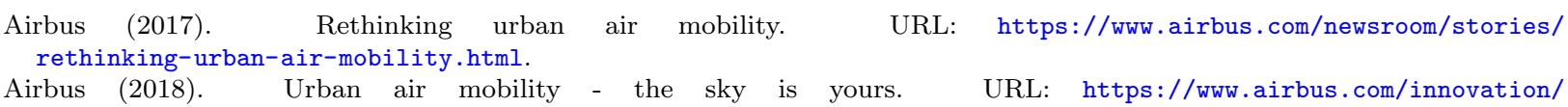
Urban-air-mobility-the-sky-is-yours.html. 
Antcliff, K. R., Moore, M. D., \& Goodrich, K. H. (2016). Silicon valley as an early adopter for on-demand civil VTOL operations. In 16th AIAA Aviation Technology, Integration, and Operations Conference (p. 3466).

Bansal, P., Kockelman, K. M., \& Singh, A. (2016). Assessing public opinions of and interest in new vehicle technologies: An Austin perspective. Transportation Research Part C: Emerging Technologies, 67, 1-14.

Baptista, P., Melo, S., \& Rolim, C. (2014). Energy, environmental and mobility impacts of car-sharing systems. empirical results from lisbon, portugal. Procedia-Social and Behavioral Sciences, 111, 28-37.

Baumgartner, H., \& Steenkamp, J.-B. E. (2001). Response styles in marketing research: A cross-national investigation. Journal of Marketing Research, 38,143-156. URL: https://doi.org/10.1509/jmkr.38.2.143.18840. doi:10.1509/jmkr.38.2.143. 18840. arXiv:https://doi.org/10.1509/jmkr.38.2.143.18840.

Bierlaire, M. (2003). Biogeme: a free package for the estimation of discrete choice models. In Swiss Transport Research Conference TRANSP-OR-CONF-2006-048.

Bimbraw, K. (2015). Autonomous cars: Past, present and future a review of the developments in the last century, the present scenario and the expected future of autonomous vehicle technology. In Informatics in Control, Automation and Robotics (ICINCO), 2015 12th International Conference on (pp. 191-198). IEEE volume 1.

Bjørner, T. (2015). A priori user acceptance and the perceived driving pleasure in semi-autonomous and autonomous vehicles. In European Transport Conference 2015.

Boucher, P. (2016). 'You wouldn't have your granny using them': Drawing boundaries between acceptable and unacceptable applications of civil drones. Science and Engineering Ethics, 22, 1391-1418. URL: https://doi.org/10.1007/ s11948-015-9720-7.

Chamata, J. (2017). Factors delaying the adoption of civil drones: A primitive framework. The International Technology Management Review, 6, 125-132.

Choi, J. K., \& Ji, Y. G. (2015). Investigating the importance of trust on adopting an autonomous vehicle. International Journal of Human-Computer Interaction, 31, 692-702.

Clements, L. M., \& Kockelman, K. M. (2017). Economic effects of automated vehicles. Transportation Research Record: Journal of the Transportation Research Board, (pp. 106-114).

Clothier, R. A., Greer, D. A., Greer, D. G., \& Mehta, A. M. (2015). Risk perception and the public acceptance of drones. Risk Analysis, 35, 1167-1183

Cohen, M. M. (1996). The Vertiport as an Urban Design Problem. Technical Report SAE Technical Paper.

755 Connected Automated Driving EU (2017). New study on user acceptance of driverless cars released. //connectedautomateddriving.eu/mediaroom/nes-study-user-acceptance-driverless-cars-released/. Costello, A. B., \& Osborne, J. W. (2005). Best practices in exploratory factor analysis: Four recommendations for getting the most from your analysis. Practical Assessment, Research \&5 Evaluation, 10, 1-9.

Davis, F. D., Bagozzi, R. P., \& Warshaw, P. R. (1989). User acceptance of computer technology: a comparison of two theoretical models. Management Science, 35, 982-1003.

Deloitte Analytics Institute (2017). Autonomous driving in Germany how to convince customers. URL: https://www2. deloitte.com/content/dam/Deloitte/de/Documents/consumer-industrial-products/Autonomous-driving-in-Germany_ PoV.pdf/.

Dolnicar, S. (2013). Asking good survey questions. Journal of Travel Research, 52, 551-574.

Efthymiou, D., Antoniou, C., \& Waddell, P. (2013). Factors affecting the adoption of vehicle sharing systems by young drivers. Transport Policy, 29, 64-73.

Euromonitor International (2017). Munich city review. URL: http://www.euromonitor.com/munich-city-review/report.

Fabrigar, L. R., Wegener, D. T., MacCallum, R. C., \& Strahan, E. J. (1999). Evaluating the use of exploratory factor analysis in psychological research. Psychological methods, 4, 272.

770 Fadhil, D. N. (2018). A GIS-Based Analysis for Selecting Ground Infrastructure Locations for Urban Air Mobility. Master's Thesis Technical University of Munich.

Fagnant, D. J., \& Kockelman, K. (2015). Preparing a nation for autonomous vehicles: opportunities, barriers and policy recommendations. Transportation Research Part A: Policy and Practice, 77, 167-181.

Fagnant, D. J., \& Kockelman, K. M. (2014). The travel and environmental implications of shared autonomous vehicles, using agent-based model scenarios. Transportation Research Part C: Emerging Technologies, 40, 1-13.

Fu, M., Rothfeld, R., \& Antoniou, C. (2019). Exploring preferences for transportation modes in an urban air mobility environment: a Munich case study. Transportation Research Record: Journal of the Transportation Research Board, In Press.

Gaggi, S. (2017). Driverless cars and user acceptance. URL: https://mobilitybehaviour.eu/2017/07/26/ driverless-cars-and-user-acceptance/.

Garrow, L. A., German, B., Mokhtarian, P., Daskilewicz, M., Douthat, T. H., \& Binder, R. (2018). If you fly it, will commuters come? A survey to model demand for e-VTOL urban air trips. In 2018 Aviation Technology, Integration, and Operations Conference (p. 2882).

Ghazizadeh, M., Lee, J. D., \& Boyle, L. N. (2012). Extending the technology acceptance model to assess automation. Cognition, Technology \&3 Work, 14, 39-49.

Hohenberger, C., Spörrle, M., \& Welpe, I. M. (2016). How and why do men and women differ in their willingness to use automated cars? the influence of emotions across different age groups. Transportation Research Part A: Policy and Practice, 94, 374-385

Jenkins, S., Linden, E., \& Wittmer, A. (2018). Autonomous Mobility - An Application of the Technology Acceptance Model. URL: https://cfac.unisg.ch/en/research-publications-consulting/cfac-working-paper-series.

Kaan, J. (2017). User acceptance of autonomous vehicles: Factors \& implications, . URL: https://repository.tudelft.nl. 
Kaiser, H. F. (1958). The varimax criterion for analytic rotation in factor analysis. Psychometrika, 23, 187-200.

KPMG (2018). Autonomous vehicles readiness index. URL: https://assets.kpmg.com/content/dam/kpmg/tw/pdf/2018/03/ KPMG-Autonomous-Vehicle-Readiness-Index.pdf.

795 Kreimeier, M., \& Stumpf, E. (2017). Market volume estimation of thin-haul on-demand air mobility services in Germany. In 17th AIAA Aviation Technology, Integration, and Operations Conference (p. 3282).

Krueger, R., Rashidi, T. H., \& Rose, J. M. (2016). Preferences for shared autonomous vehicles. Transportation Research Part C: Emerging Technologies, 69, 343 - 355. URL: http://www.sciencedirect.com/science/article/pii/S0968090X16300870.

Kyriakidis, M., Happee, R., \& de Winter, J. C. (2015). Public opinion on automated driving: Results of an international questionnaire among 5000 respondents. Transportation Research Part F: Traffic Psychology and Behaviour, 32, $127-140$.

Lidynia, C., Philipsen, R., \& Ziefle, M. (2017). Droning on about dronesacceptance of and perceived barriers to drones in civil usage contexts. In Advances in Human Factors in Robots and Unmanned Systems (pp. 317-329). Springer.

Likert, R. (1932). A technique for the measurement of attitudes. Archives of psychology, 20, 5-55.

MacSween, S. (2003). A public opinion survey-unmanned aerial vehicles for cargo, commercial, and passenger transportation. In 2nd AIAA" Unmanned Unlimited" Conf. and Workshop ES Exhibit (p. 6519).

McFadden, D. (2001). Economic choices. American economic review, 91, 351-378.

Merat, N., Madigan, R., \& Nordhoff, S. (2016). Human factors, user requirements, and user acceptance of ride-sharing in automated vehicles. In International Transport Forum Roundtable on Cooperative Mobility Systems and Automated Driving (pp. 6-7).

810 Mokhtarian, P. L., Ory, D. T., \& Cao, X. (2009). Shopping-related attitudes: a factor and cluster analysis of Northern California shoppers. Environment and Planning B: Planning and Design, 36, 204-228.

NASA (2018). Urban Air Mobility (UAM) Market Study. Technical Report. URL: https://ntrs.nasa.gov/archive/nasa/ casi.ntrs.nasa.gov/20190001472.pdf.

NASA (2019). Urban Air Mobility (UAM) Market Study. URL: https://ntrs.nasa.gov/archive/nasa/casi.ntrs.nasa.gov/ 20190026762.pdf.

Nees, M. A. (2016). Acceptance of self-driving cars: an examination of idealized versus realistic portrayals with a self-driving car acceptance scale. In Proceedings of the Human Factors and Ergonomics Society Annual Meeting (pp. 1449-1453). SAGE Publications Sage CA: Los Angeles, CA volume 60.

Payre, W., Cestac, J., \& Delhomme, P. (2014). Intention to use a fully automated car: Attitudes and a priori acceptability. Transportation Research Part F: Traffic Psychology and Behaviour, 27, 252-263.

Peeta, S., Paz, A., \& DeLaurentis, D. (2008). Stated preference analysis of a new very light jet based on-demand air service. Transportation Research Part A: Policy and Practice, 42, 629 - 645. URL: http://www.sciencedirect.com/science/ article/pii/S096585640800013X.

Piao, J., McDonald, M., Hounsell, N., Graindorge, M., Graindorge, T., \& Malhene, N. (2016). Public views towards implementation of automated vehicles in urban areas. Transportation Research Procedia, 14, 2168-2177.

Porsche Consulting (2018). The future of vertical mobility: Sizing the market for passenger, inspection, and good services until 2035.

R Core Team (2019). R: A Language and Environment for Statistical Computing. R Foundation for Statistical Computing Vienna, Austria. URL: http://www.R-project.org/.

Riad, M.-I., Jaradat, m.-i., Fagih, K., \& S Faqih, M. (2014). Investigating the moderating effects of gender and self-efficacy in the context of mobile payment adoption: A developing country perspective. International Journal of Business and Management, 9 .

Rödel, C., Stadler, S., Meschtscherjakov, A., \& Tscheligi, M. (2014). Towards autonomous cars: the effect of autonomy levels on acceptance and user experience. In Proceedings of the 6th International Conference on Automotive User Interfaces and Interactive Vehicular Applications (pp. 1-8). ACM.

Rothfeld, R. L., Balac, M., Ploetner, K. O., \& Antoniou, C. (2018). Initial Analysis of Urban Air Mobility's Transport Performance in Sioux Falls. In AIAA AVIATION, Modeling and Simulation for Unmanned and Personal Aerial Vehicle Operations. Atlanta.

Rychel, A. (2016). Cultural divides: How acceptance of driverless cars varies globally. URL: https://www.2025ad.com/latest/ driverless-cars-acceptance/.

Schoettle, B., \& Sivak, M. (2014). A survey of public opinion about autonomous and self-driving vehicles in the US, the UK, and Australia.

Shamiyeh, M., Bijewitz, J., \& Hornung, M. (2017). A review of recent personal air vehicle concepts. In Aerospace Europe 6th CEAS Conference.

845 Statistische Ämter des Bundes und der Länder (2014). Ergebnisse des zensus 2011. URL: https://www.zensus2011.de/DE/ Home/home_node.html.

Steele, C. M. (1995). Stereotype threat and the intellectual test performance. Journal of Personality and Social Psychology, 69,1 .

Straubinger, A., \& Verhoef, E. T. (2018). (Working Paper) Options for a Welfare Analysis of Urban Air Mobility. Hong Kong.

850 Sun, H., \& Zhang, P. (2006). The role of moderating factors in user technology acceptance. International Journal of HumanComputer Studies, 64, 53-78.

Tabachnick, B. G., Fidell, L. S., \& Ullman, J. B. (2007). Using multivariate statistics volume 5. Pearson Boston, MA.

Thipphavong, D. P., Apaza, R., Barmore, B., Battiste, V., Burian, B., Dao, Q., Feary, M., Go, S., Goodrich, K. H., Homola, J. et al. (2018). Urban air mobility airspace integration concepts and considerations. In 2018 Aviation Technology, Integration, and Operations Conference (p. 3676).

Tyrinopoulos, Y., \& Antoniou, C. (2008). Public transit user satisfaction: Variability and policy implications. Transport 
Policy, 15, 260-272.

Uber Elevate (2016). Fast-forwarding to a future of on-demand urban air transportation. URL: https://www.uber.com/ elevate.pdf.

Uber Elevate (2018). Fast-forwarding to the future of on-demand, urban air transportation. URL: https://www.uber.com/ info/elevate/.

Vascik, P. D. (2017). Systems-level analysis of On Demand Mobility for aviation. Ph.D. thesis Massachusetts Institute of Technology.

Vascik, P. D., \& Hansman, R. J. (2018). Scaling constraints for urban air mobility operations: Air traffic control, ground infrastructure, and noise. In 2018 Aviation Technology, Integration, and Operations Conference (p. 3849).

Venkatesh, V., \& Bala, H. (2008). Technology acceptance model 3 and a research agenda on interventions. Decision sciences, $39,273-315$.

Venkatesh, V., \& Davis, F. D. (2000). A theoretical extension of the technology acceptance model: Four longitudinal field studies. Management Science, 46, 186-204.

Venkatesh, V., Morris, M. G., Davis, G. B., \& Davis, F. D. (2003). User acceptance of information technology: Toward a unified view. MIS quarterly, (pp. 425-478).

Wang, Y., Xia, H., Yao, Y., \& Huang, Y. (2016). Flying eyes and hidden controllers: A qualitative study of people's privacy perceptions of civilian drones in the US. Proceedings on Privacy Enhancing Technologies, 2016, 172-190.

Yeomans, K. A., \& Golder, P. A. (1982). The guttman-kaiser criterion as a predictor of the number of common factors. The Statistician, (pp. 221-229).

Zhang, T., Tao, D., Qu, X., Zhang, X., Lin, R., \& Zhang, W. (2019). The roles of initial trust and perceived risk in publics acceptance of automated vehicles. Transportation Research Part C: Emerging Technologies, 98, 207-220. 